\title{
ADAPTIVE MODEL FOR THREE-PHASE INDUCTION MOTOR USING NEURAL NETWORKS
}

\author{
Mahmoud M. EL-kholy \\ Electrical Power and Machines Department, Faculty of Engineering, \\ Zagazig University, Zagazig, Egypt
}

\begin{abstract}
This paper proposes a method for the modeling of induction motor using neural networks. The use of artificial neural networks (ANN) in this paper is due to their benefits such as fast computation, ability of implementation, and easy interpolation. The neural network is trained by an experimental data over a wide range of voltages, frequencies and load torques. At each value of frequency and applied voltage the motor is loaded from no-load to full load. Therefore, the training data cover all the possible operating range of the motor under different frequencies and voltages. The advantages of the proposed model using ANN, is that the knowledge of the electrical parameters of the motor is not necessary, and the change in these parameters with operating conditions doesn't effect on performance of motor model. The inputs of the ANN motor model are voltage, frequency and current and the model gives the motor speed, torque and efficiency as the outputs. By these three values another motor performance characteristics can be calculated. The proposed model with (ANN) can be used in speed and torque sensorless estimation depending on the motor inputs, which will give an efficient and better performance for an induction motor.

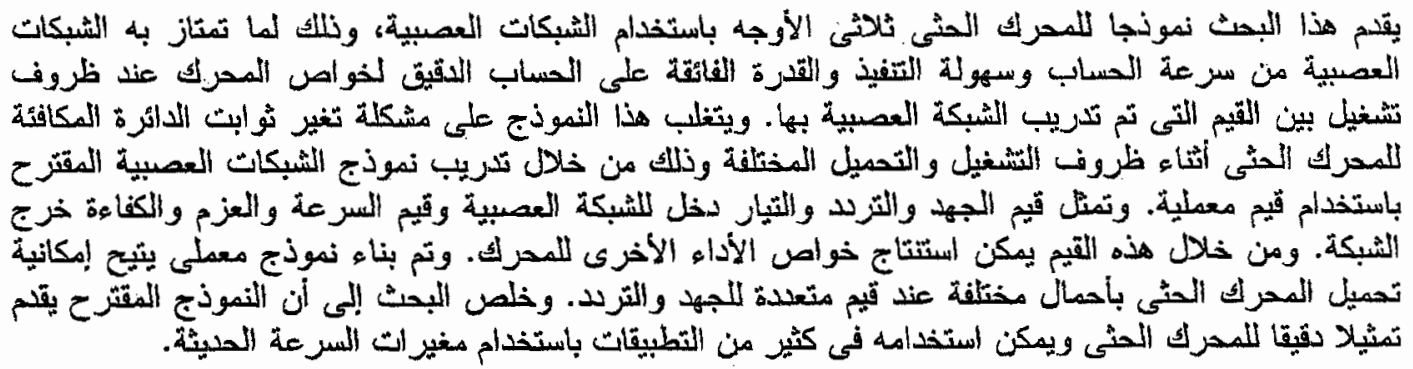

Keywords: Induction motors, induction motor modeling, induction motor control, induction motor variable speed and artificial neural networks.

\section{INTRODUCTION}

Induction motors have undergone rapid development in their usage for all industry categories. Induction motors represent over eighty percent of all electric motors used in domestic, commercial and industrial applications. The use of ANN in electrical machine field is not strange, samples about the researchers efforts in this field are introduced below. The neural network is used to have an adaptive speed control for induction motor drives with two-degree of freedom controller and its parameters adaptively tuned by neural network [1-2]. The ANN technique is also used in fault detection in induction motors and power transformers as shown in [3-4]. The neuro-fuzzy technique is used in efficiency optimization and direct torque control of induction motors [5-6]. There are many applications to use ANN in synchronous machines [7-9]. In this paper, feed - forward network and backpropagation training algorithm is used to have an adaptive model of three-phase induction motor. The neural network is trained using an experimental data over a wide range of voltages, frequencies and load torques. The inputs of ANN motor model are stator voltage, stator current and stator frequency while the outputs of the model are motor speed, torque and efficiency. Other performance characteristics of the motor can be deduced from model inputs and outputs.

\section{EXPERIMENTAL MODEL}

The description of experimental model is shown in Fig. (1). It consists of a squirrel cage induction motor of 2-hp, 4-pole and 380/660 V, frequency converter and an autotransformer. An eddy current brake is 
used to load the motor by different values of load torques. The stator of the motor is supplied by an autotransformer to control the magnitude of the stator voltage. The auto-transformer is supplied by the frequency converter to change the stator frequency.

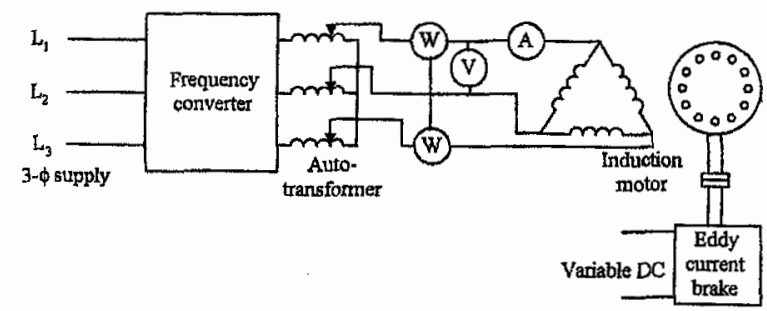

Fig. 1 Schematic diagram for the experimental model

The frequency of the frequency converter is varied to cover the range from $10 \mathrm{~Hz}$ to $100 \mathrm{~Hz}$ with a step of $10 \mathrm{~Hz}$. The eddy current brake is used to load the motor with different values of torques from no-load to full load. The autotransformer is used to vary the motor voltage at all frequencies. Table (1) shows the range of training data which are taken in the laboratory and at each frequency and voltage the motor is loaded from no load to full load.

Table 1 Range of experimental training data

\begin{tabular}{|c|c|c|c|c|c|}
\hline $\begin{array}{c}\text { Frequency } \\
\text { (Hz) }\end{array}$ & 10 & 20 & 30 & 40 & $\begin{array}{c}50,60,70, \\
80,90,100\end{array}$ \\
\hline $\begin{array}{c}\text { Voltage } \\
\text { (V) }\end{array}$ & 70 & $\begin{array}{c}75, \\
150\end{array}$ & $\begin{array}{c}110, \\
220\end{array}$ & $\begin{array}{c}75, \\
150,\end{array}$ & $\begin{array}{c}180,220, \\
260,340 \\
, 380\end{array}$ \\
\hline
\end{tabular}

\section{ANN MODEL}

The ANN model is built up using the feed forward network and back-propagation training algorithm. Back-propagation technique is used in this research due to its ability to deduce relations between input and output. Properly trained back-propagation networks tend to give reasonable outputs when presented with inputs that they have never seen. Typically, a new input leads to an output similar to the correct output. This generalization property makes it possible to train a network on a representative set of input and target pairs. There are generally four steps in the training process:

1. Sample the training data

2. Create the network object

3. Train the network

4. Simulate the network response to new inputs

The ANN network here consists of three layers two of them are hidden layers (one of them taking the input), and the third layer is the output one. According to the back-propagation technique the first and second layers consist of a number of neurons, each of them contains Tan-Sigmoid (tansig) transfer function. This is due to the ability of Tan-Sigmoid function to approximate the function between any training data, but in limited range. The last layer contains neurons of pure-line (purelin) transfer function, because if linear output neurons are used the network outputs can take any value.

The ANN model has three inputs (motor voltage, frequency and current) and three outputs (motor speed, torque and efficiency) as shown in Fig. (2).

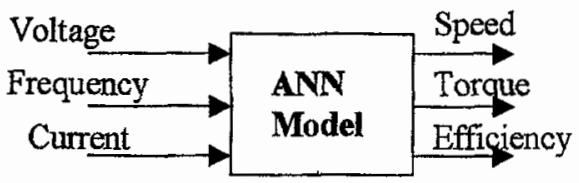

Fig. 2 Block diagram of motor model

The ANN model is trained by real values of input and target pairs coming from laboratory tests, which are described in previous section. The training data enter the network as arrays.

Inputs are written as:

$$
\begin{aligned}
P=[\mathrm{V} ; \mathbf{f} ; \mathbf{I}] \\
\quad \mathrm{P}=\left[\begin{array}{c}
\mathrm{V}_{\mathbf{1}} \ldots \ldots \ldots \ldots . \mathrm{V}_{\mathbf{n}} \\
\mathrm{f}_{\mathbf{1}} \ldots \ldots \ldots \ldots \ldots . \mathrm{f}_{\mathbf{n}} \\
\mathrm{I}_{\mathbf{1}} \ldots \ldots \ldots \ldots \ldots \mathrm{I}_{\mathrm{n}}
\end{array}\right]
\end{aligned}
$$

The targets are written as:

$$
\begin{aligned}
& \mathrm{T}=\left[\mathbf{n} ; \mathrm{T}_{\mathrm{d}} ; \text { eff }\right] \\
& \mathrm{T}=\left[\begin{array}{l}
\mathbf{n}_{\mathbf{1}} \ldots \ldots \ldots \ldots \ldots . \mathrm{n}_{\mathrm{n}} \\
\mathrm{T}_{\mathrm{d} \mathbf{1}} \ldots \ldots \ldots \ldots \ldots . . \mathrm{T}_{\mathrm{dn}} \\
\text { eff }_{1} \ldots \ldots \ldots \ldots \ldots \mathrm{eff}_{\mathrm{n}}
\end{array}\right]
\end{aligned}
$$

The network is trained to obtain the nearest output to the target. During training the weights (the input weights and layer weights) and biases of the network are iteratively adjusted to minimize the network performance function. The default performance function for feed-forward networks is the mean square error (mse), which is the average squared error between the network outputs and the target outputs. The net is properly learning with the aid of the training data (Input/Target) pairs. The training process is done with a certain number of iterations (epochs), which should be specified in the net algorithm, with a certain performance goal. Finally, the network can deduce any output with certain inputs for all the ranges in the training data.

\section{RESULTS}

The results of this research are introduced in the form of comparisons among experimental, theoretical and ANN models. Figure (3) shows the variation of mean square error with numbers of epochs. Figures (4-21) 
show samples of results of varying speed, load torque and efficiency with input current at $(10 \mathrm{~Hz}, 70 \mathrm{~V})$, $(30 \mathrm{~Hz}, 110 \mathrm{~V}, 220 \mathrm{~V}),(50 \mathrm{~Hz}, 180 \mathrm{~V}, 380 \mathrm{~V}),(60 \mathrm{~Hz}$, $300 \mathrm{~V}, 380 \mathrm{~V}),(80 \mathrm{~Hz}, 300 \mathrm{~V}, 380 \mathrm{~V})$ and $(100 \mathrm{~Hz}$, $300 \mathrm{~V}, 220 \mathrm{~V}$, respectively. These curves are samples of experimental data. The agreement between experimental and ANN curves show the great benefit of ANN model to give motor characteristics at any operating point. The errors between theoretical and experimental curves show the disadvantages of conventional equivalent circuit of induction motor due to the variation of motor parameters with different loading conditions and these parameters must be modified at different loading conditions. The motor parameters, which are obtained from $\mathrm{DC}$, noload and blocked rotor tests, are shown in Appendix 1. It is noticed from all the curves that, the ANN model is so efficient for all cases and operating conditions.

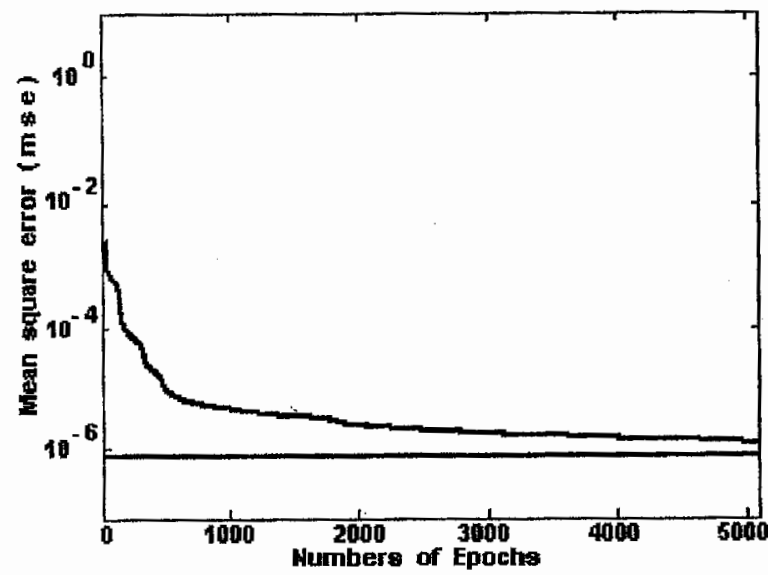

Fig. 3 Variation of mean square error with numbers of epochs

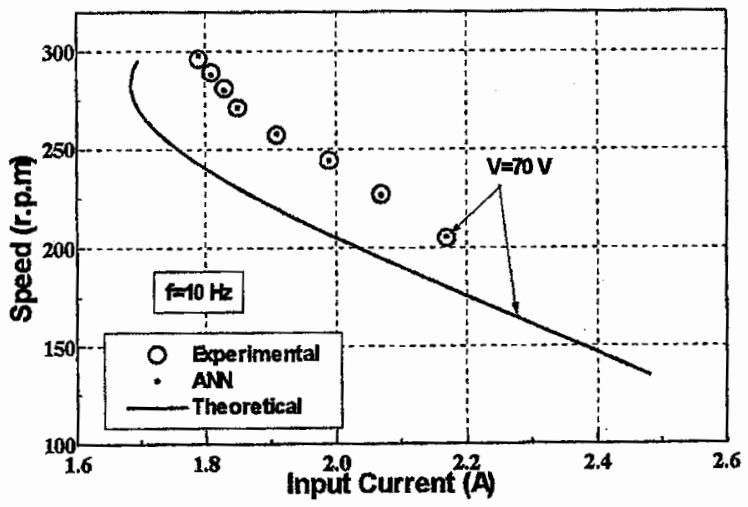

Fig. 4 Variation of speed with input current at $10 \mathrm{~Hz}$ and $70 \mathrm{~V}$

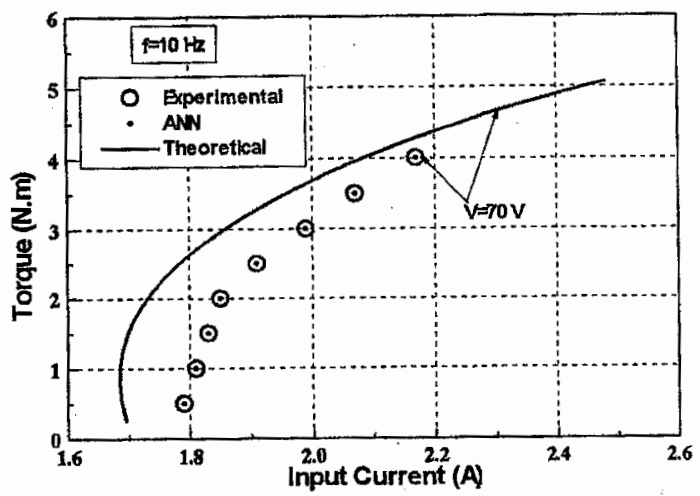

Fig. 5 Variation of toque with input current at $10 \mathrm{~Hz}$ and $70 \mathrm{~V}$

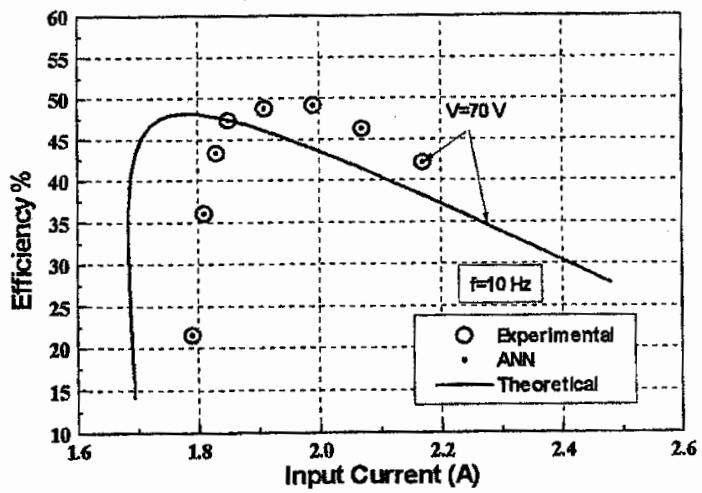

Fig. 6 Variation of efficiency with input current at $10 \mathrm{~Hz}$ and $70 \mathrm{~V}$

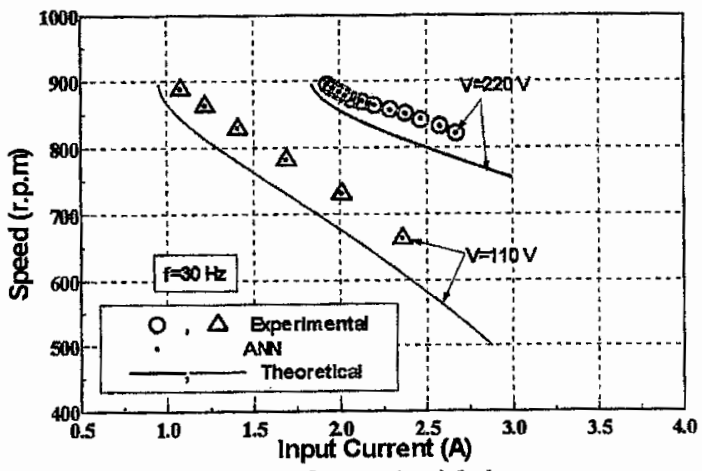

Fig. 7 Variation of speed with input current at $30 \mathrm{~Hz}$ and different voltages

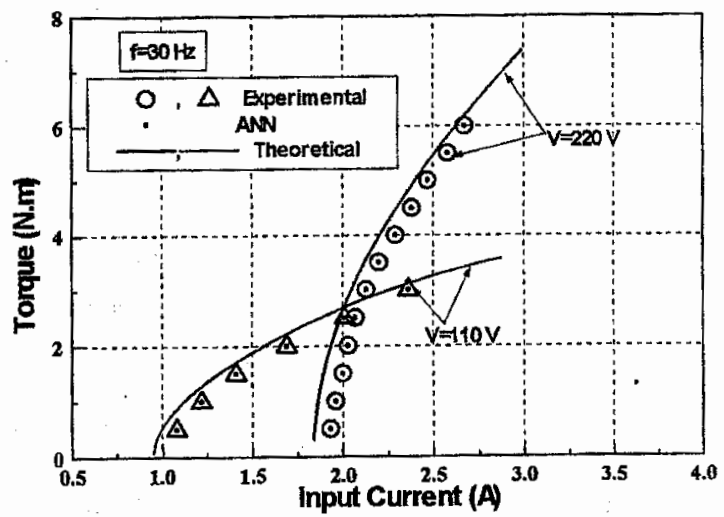

Fig. 8 Variation of torque with input current at $30 \mathrm{~Hz}$ and different voltages 


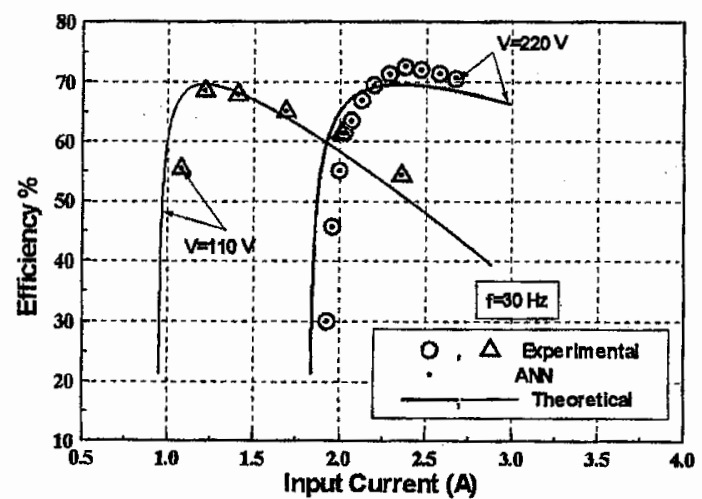

Fig. 9 Variation of efficiency with input current at $30 \mathrm{~Hz}$ and different voltages

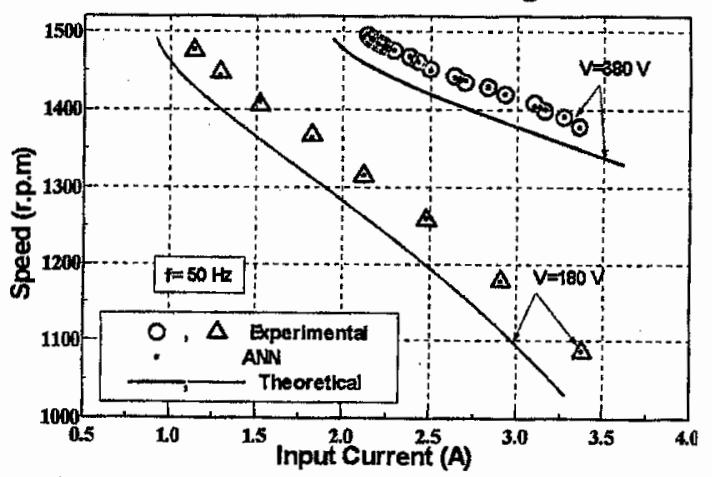

Fig. 10 Variation of speed with input current at $50 \mathrm{~Hz}$ and different voltages

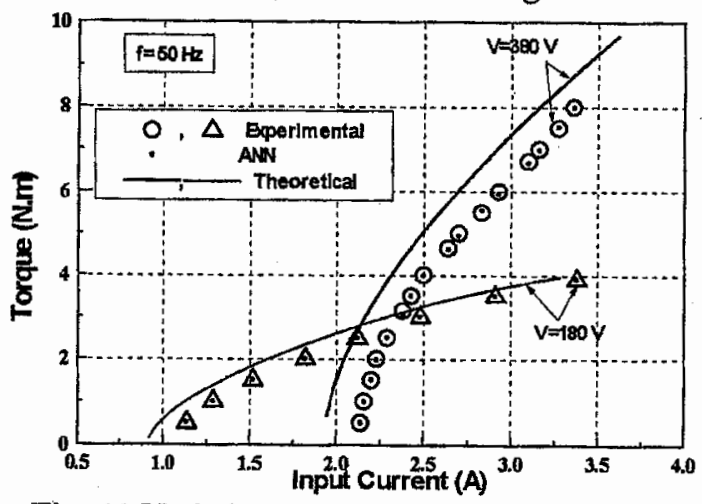

Fig. 11 Variation of torque with input current at $50 \mathrm{~Hz}$ and different voltages

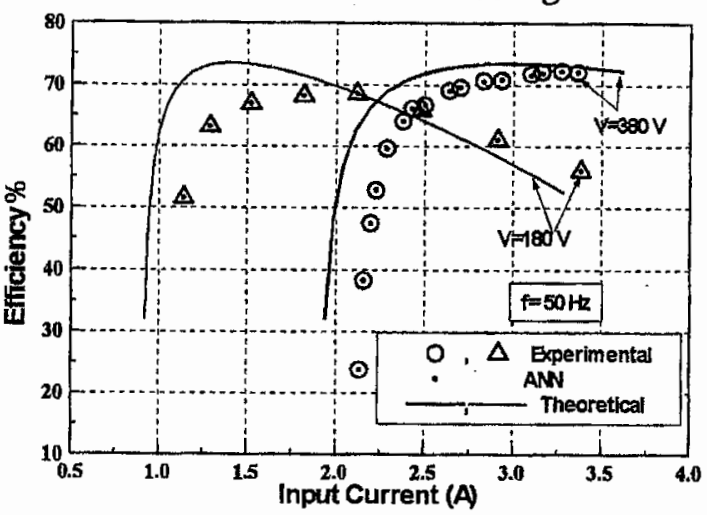

Fig. 12 Variation of efficiency with input current at $50 \mathrm{~Hz}$ and different voltages

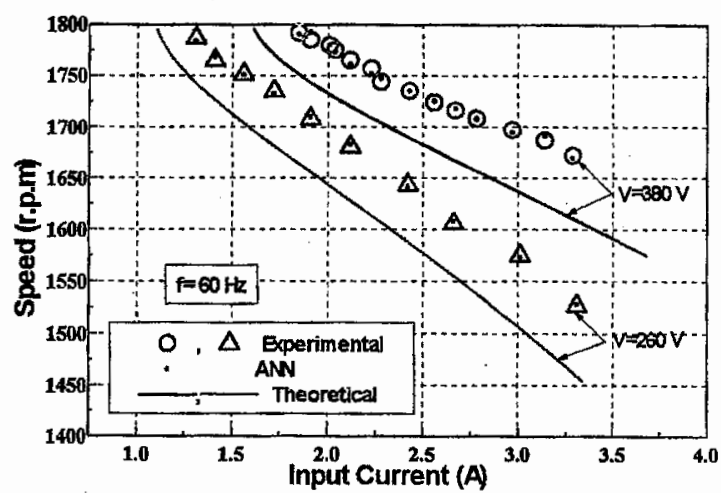

Fig. 13 Variation of speed with input current at $60 \mathrm{~Hz}$ and different voltages

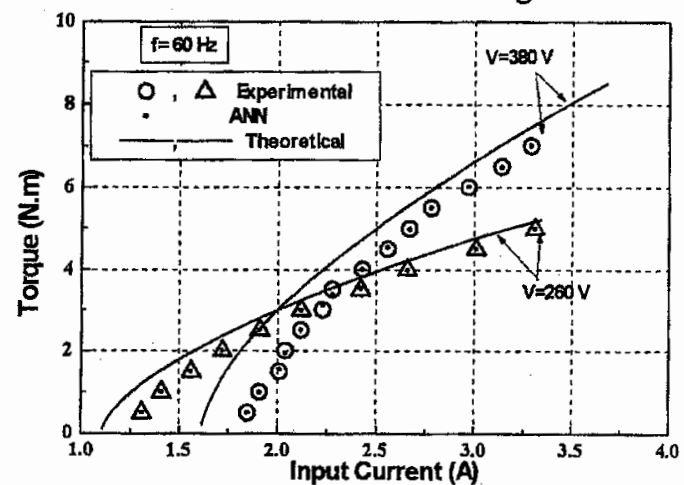

Fig. 14 Variation of torque with input current at $60 \mathrm{~Hz}$ and different voltages

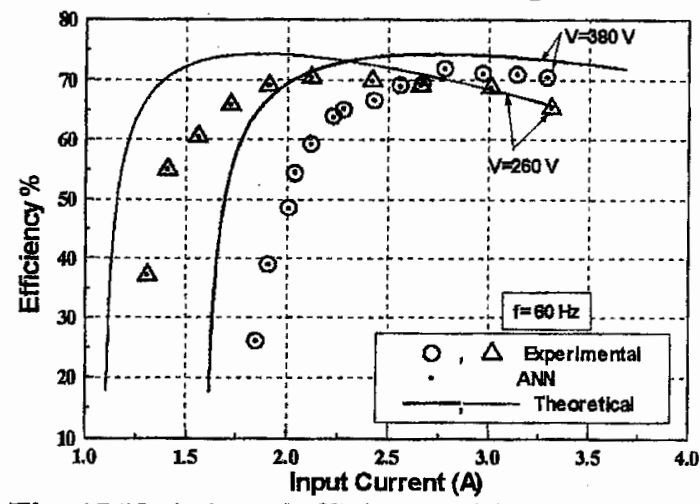

Fig. 15 Variation of efficiency with input current at $60 \mathrm{~Hz}$ and different voltages

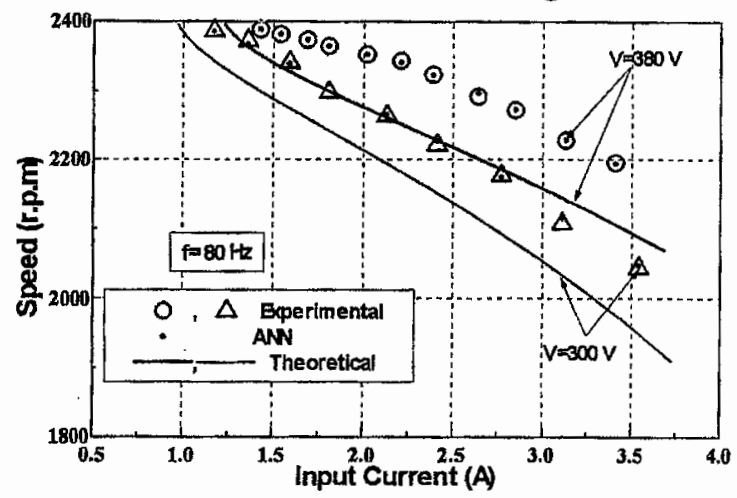

Fig. 16 Variation of speed with input current at $80 \mathrm{~Hz}$ and different voltages 


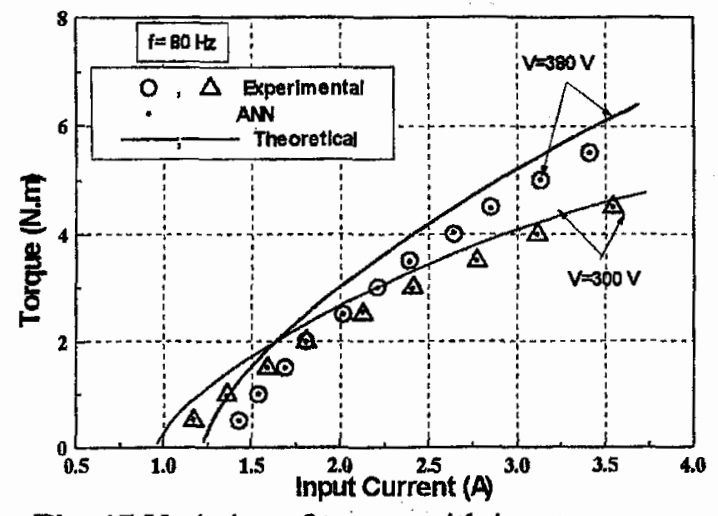

Fig. 17 Variation of torque with input current at $80 \mathrm{~Hz}$ and different voltages

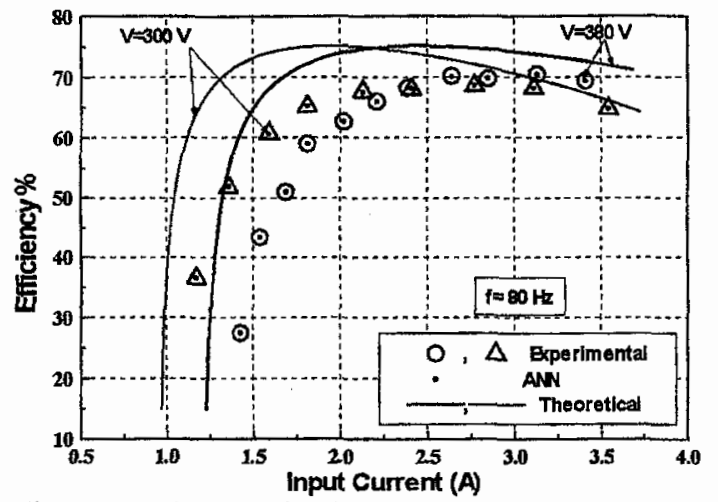

Fig. 18 Variation of efficiency with input current at $80 \mathrm{~Hz}$ and different voltages

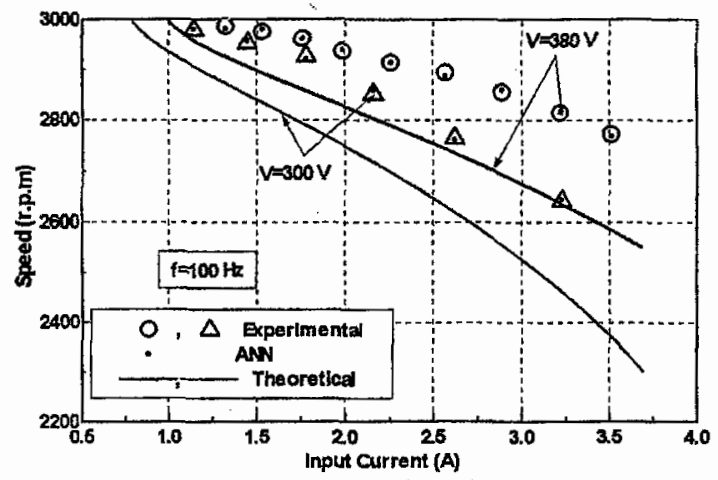

Fig. 19 Variation of speed with input current at $100 \mathrm{~Hz}$ and different voltages

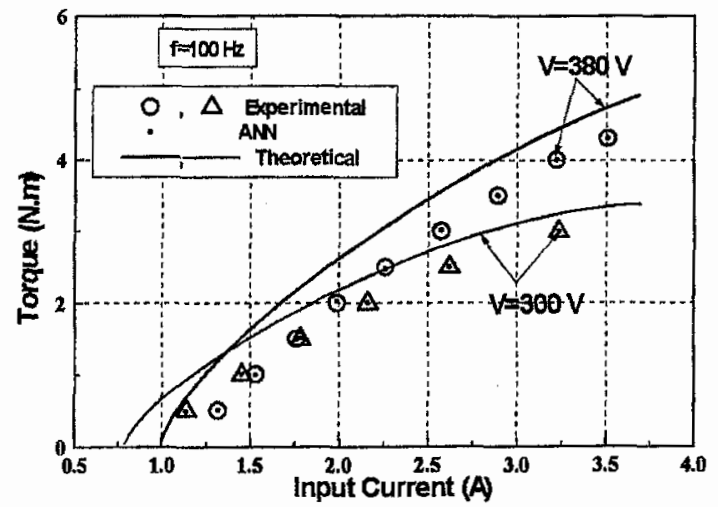

Fig. 20 Variation of torque with input current at $100 \mathrm{~Hz}$ and different voltages

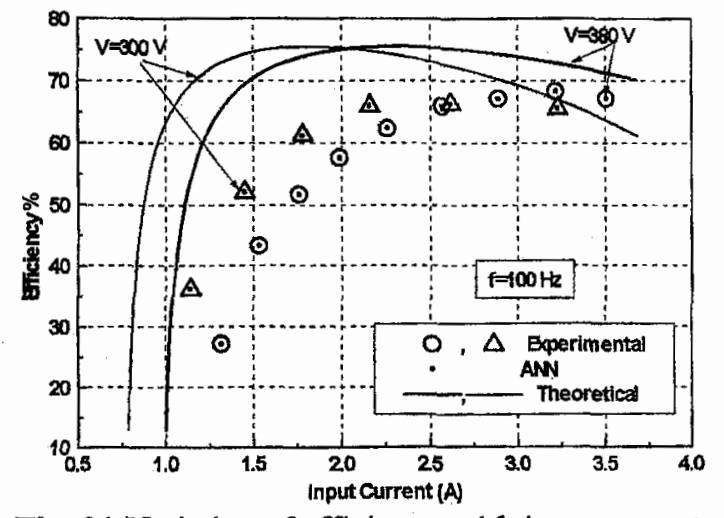

Fig. 21 Variation of efficiency with input current at $100 \mathrm{~Hz}$ and different voltages

\section{CONCLUSIONS}

The ANN model is an accurate model for an induction motor as shown from the agreement between the experimental and ANN results. It can be deduced or verified from this paper that, there is no more need for the equations of induction motor equivalent circuit because they can be replaced by this simple adaptive model of induction motor using the ANN. This model depends on real values coming from experimental laboratory tests, which introduce the inputs and targets of this model and cover all possible operating cases. This model can be used in sensorless speed estimation depending on the motor input variables with the ability of ANN for better computation, easy implementation, and efficient interpolation. This method gives all motor performance characteristics by measuring the input current, voltage and motor frequency without any need of a tachometer to measure speed or a torque transducer to measure motor torque and this increases the motor reliability.

\section{REFERENCES}

[1] Y.S. Kung, C.M. Liaw, and M.S. Ouyang, “ Adaptive speed control for induction motor drives using neural networks", IEEE Trans. Ind. Elec., Vol. 42, No. 1, pp. 25 - 32, Feb. 1995.

[2] K.K. Shyu, H.J. Sheih, and S.S. Fu,“ Model reference adaptive speed control for induction motor drive using neural networks", IEEE Trans. Ind. Elec., Vol. 45, No. 1, pp. $180-182$, Feb. 1998.

[3] K. Gulez, B. Karlik, and S. Vakkas Usten," Designing Artificial Neural Networks for Fault Detection in Induction Motors with the TMS320C30 DAP", ESIEE, Paris, TEXAS INSTRUMENTS, September 1996.

[4] Z. Wang," Artificial Intelligence Applications in the Diagnosis of Power Transformer Incipient Faults", P.H.D. August 8, 2000, Blacksburg, Virginia. 
[5] B.K. Bose, N.R. Patel, and K. Rajashekara, " A neuro-fuzzy-based on-line-efficiency optimization control of a stator flux-oriented direct vector-controlled induction motor drive", IEEE Trans. Ind. Elec., Vol. 44, No. 2, pp. 270 273, April 1997.

[6] P.Z. Grabowski, M.P. Kazmierkowski, Bose, and Blaabjerg, "A simple direct-torque neuro-fuzzy control of PWM-Inverter-fed induction motor drive", IEEE Trans. Ind. Elec., Vol. 47, No. 4, pp. $863-869$, August 2000.

[7] S. Pillutla, and A. Keyhani, Neural Network Based Saturation Model for Round Rotor Synchronous Generator", IEEE Trans. Energy Conversion, No., P.E-161-EC-0-08-1998.

[8] S. Pillutla, and A. Keyhani," Development and Implementation of Neural Network Observers to Estimate the State Vector of a Synchronous
Generator from On - line operating Data”, IEEE Trans. Energy Conversion, No. 99 WM273.

[9] S. Pillutla, A. Keyhani, and I. Kamwa, " Neural Network Observers for on-line Tracking of Synchronous Generator parameters", IEEE Trans. Energy Conversion, Vol. 14, No. 1, March 1999.

\section{Appendix}

The nameplate data and parameters of experimental motor are: $2 \mathrm{hp}, 4$-pole, $380 / 660 \mathrm{~V}$ and $3.5 / 2 \mathrm{~A}$

$\begin{array}{ll}\text { Stator resistance } & =15.655 \Omega \\ \text { Stator leakage inductance } & =0.0768 \mathrm{H} \\ \text { Magnetizing inductance } & =1.02011 \mathrm{H} \\ \text { Referred rotor resistance } & =2.30917 \Omega \\ \text { Referred rotor leakage inductance } & =0.0768 \mathrm{H} \\ \text { Core loss resistance } & =2250 \Omega\end{array}$

